\title{
RELIABILITY ASSESSMENT OF THE DEFENSE AUTOMATED NEUROBEHAVIORAL ASSESSMENT (DANA) IN EXTREME OPERATIONAL ENVIRONMENTS
}

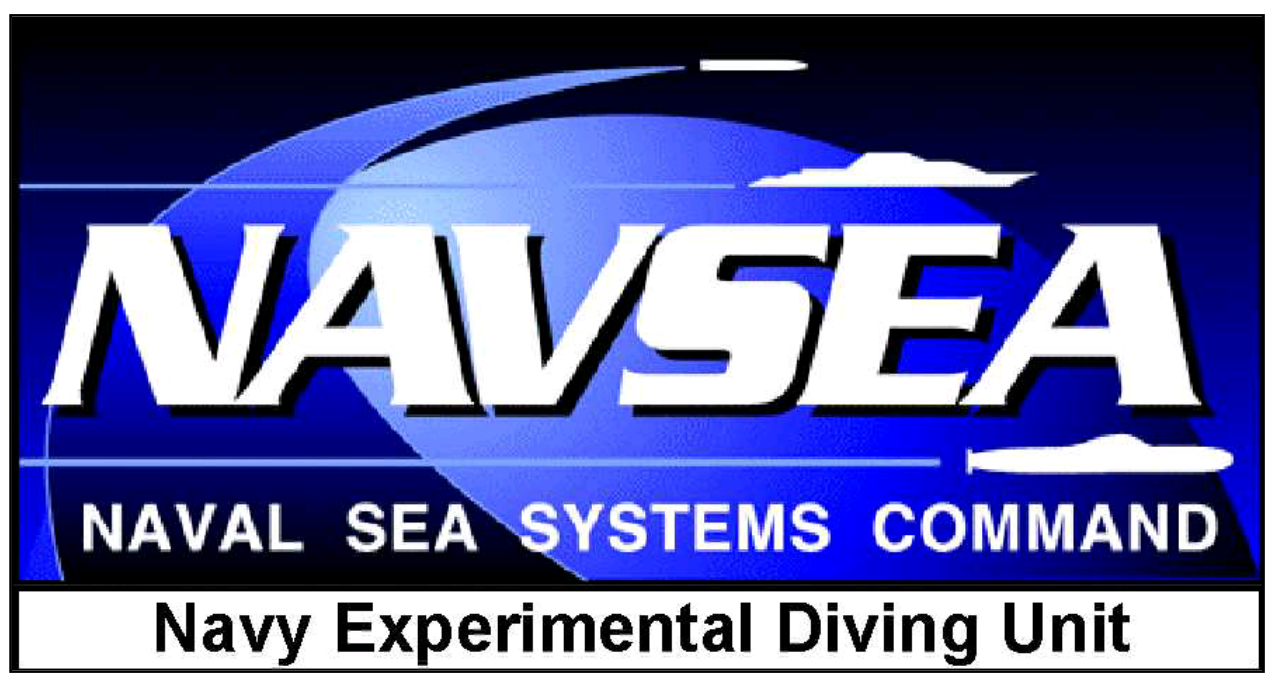

Authors:

F. Jay Haran, LT, Ph.D., MSC, USN Amelia Lovelace, B.S, John Florian, Ph.D.
Distribution Statement A:

Approved for Public Release Distribution is Unlimited 


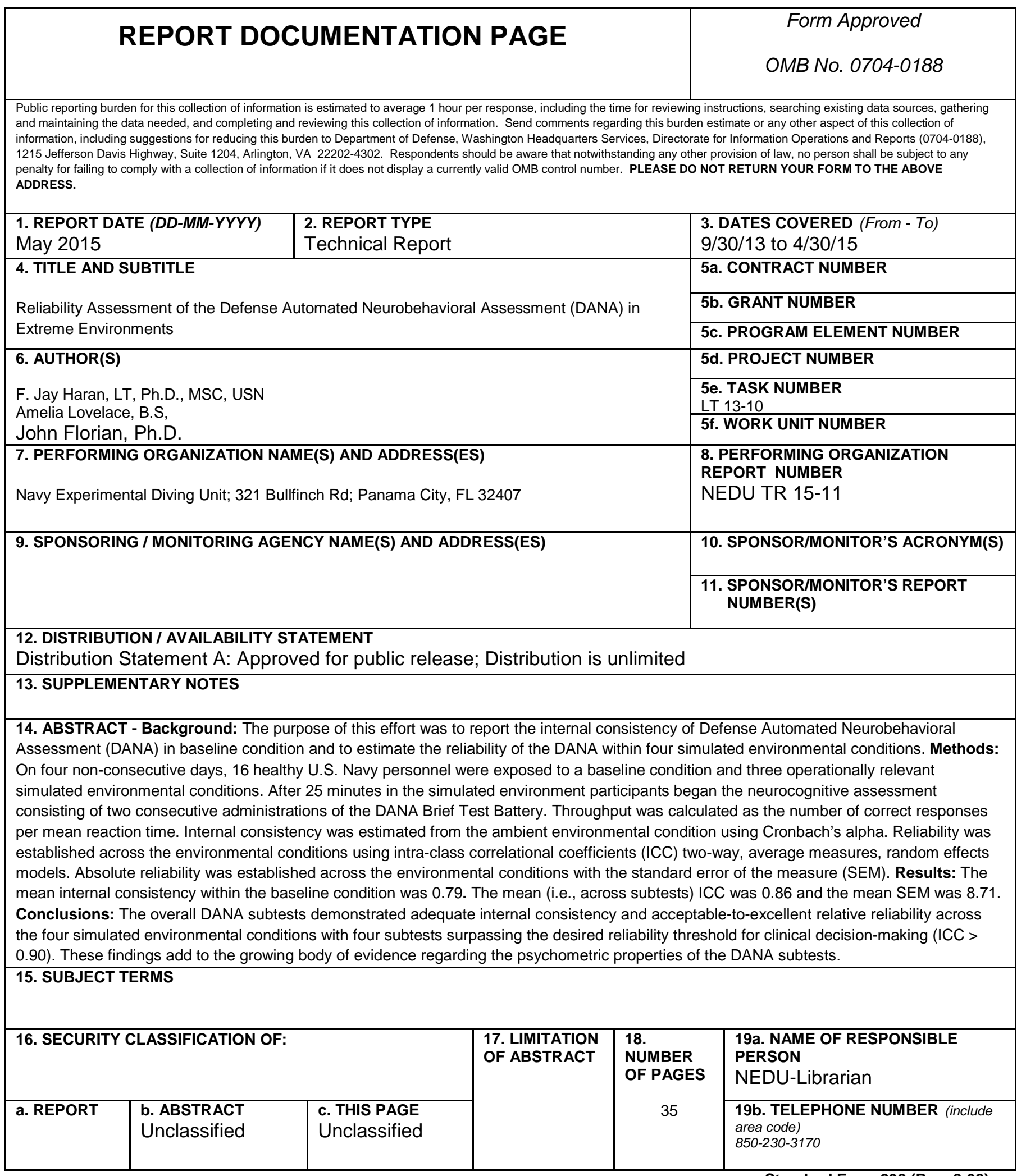




\section{CONTENTS}

Page No.

DD FORM 298

CONTENTS

ii

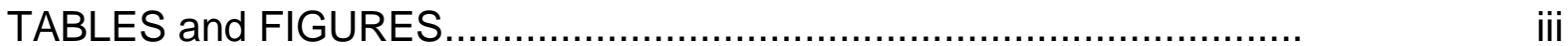



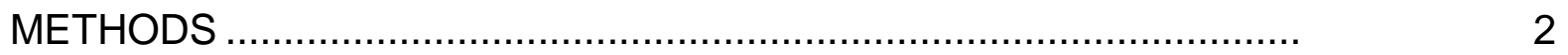

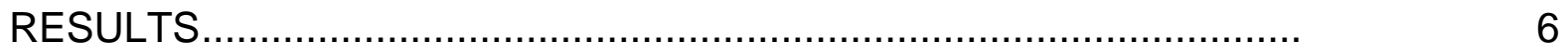



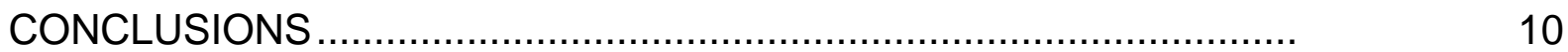

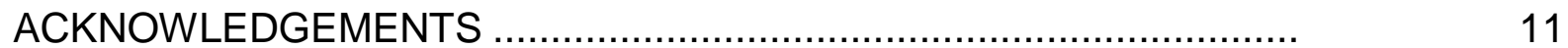

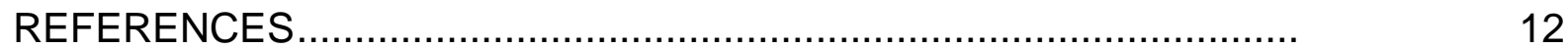

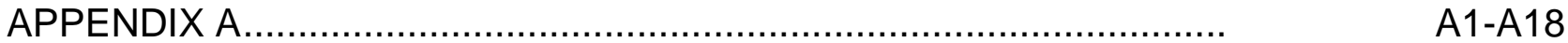




\section{TABLES}

Table No.

Page No.

1

2

3

4

5
Test conditions for neurocognitive testing

3

DANA Rapid Battery Subset Descriptions 4

Data Cleaning Cutoffs for Reaction Times 5

Descriptive statistics for the DANA subtests

7

DANA internal consistency and reliability metrics across environmental conditions 


\section{INTRODUCTION}

Neuropsychological assessments are useful for detecting both impaired and optimal cognitive functioning. Neuropsychological tests have not changed greatly since the days when Halstead and Reitan introduced standardized cognitive testing. ${ }^{1}$ Now, as then, the major drawbacks in cognitive assessment are the time it takes to administer the battery as well as the expertise required to administer, score, and interpret the tests. Several computerized neurocognitive assessment tools (NCAT) based upon standardized neuropsychological tests of speed and accuracy have been developed to overcome these limitations. The Automated Neuropsychological Assessment Metrics (ANAM) was the first widely utilized automated battery. ${ }^{2}$ Initially sponsored by US Department of Defense (DoD) and later adopted for baseline testing of service members prior to deployment, ANAM is widely used with over 1.5 million tests administered in the past five years. ${ }^{3}$

In January 2009, the U.S. Navy Bureau of Medicine and Surgery identified a need to enhance existing battlefield concussion assessment and requested the development of a durable, portable, and field-hardened NCAT to provide a practical means to conduct neurocognitive and psychological assessment in field deployment settings. The purpose of combining neurocognitive and psychological assessment was to permit more comprehensive evaluation of the broad range of problems that may be encountered during combat deployment. The Defense Automated Neurobehavioral Assessment (DANA) was designed to meet this need. The DANA was specifically developed to be field deployable under a wide range of environmental conditions.

A recent effort reported that the specific subtests with the DANA battery, simple reaction time (SRT1), simple reaction time repeated (SRT2), procedural reaction time (PRO), coded substitution (CDS), and coded substitution delayed (CDD), on average had moderate to good (i.e., 0.50-0.75) concurrent validity with the ANAM for throughput and median reaction time. ${ }^{4}$ The test-retest reliability of the simple reaction time for DANA was superior to the ANAM, 0.75 vs. 0.64 and 0.70 vs.0.36, for median reaction time and throughput respectively. ${ }^{4}$

A second study reported the internal consistency and reliability of DANA's hardware and software functioning under challenging field conditions. These environments included the arctic (Thule Air Force Base-Greenland in the winter), jungle (U.S. Marine Corps Jungle Warfare Training Center-Okinawa, Japan, in the summer), at altitude (U.S. Marine Corps Mountain Warfare Training Center-Bridgeport, CA, approximately 3,000 $\mathrm{m}$ ), desert (U.S. Marine Corps Desert Warfare Training Center-Twentynine Palms, CA, in the summer), and shipboard (USS George Washington during high seas in the Western Pacific). The split-half reliability correlations for DANA subtests were within acceptable ranges, and were comparable to those reported for the ANAM. ${ }^{5}$ However, the study did not use the same participants across field conditions, and the reported reliability estimates cannot be used to assume reliability across the field conditions, but should be interpreted as an estimate of test-retest reliability. 
Thus, the objective of this effort was two-fold:

1. To estimate the internal consistency of the DANA within a baseline ambient environmental condition.

2. To estimate the reliability, both absolute and relative, of the DANA across four simulated environmental conditions in the same personnel.

\section{Participants}

\section{METHODS}

The NEDU Institutional Review Board (IRB) approved protocol number 1423/40063,"Evaluation of the Defense Automated Neurobehavioral Assessment (DANA) in Extreme Environments." The participants for this effort consisted of sixteen male U.S. Navy personnel from NEDU. Navy personnel were recruited for this effort via direct solicitation by the Task Leader through email correspondence or in a group setting with the NEDU IRB ombudsman present. Participants were briefed, provided with the protocol, encouraged to read it, and provided with the opportunity to ask questions prior to giving written informed consent. Participants were assigned identification numbers after they enrolled. Files and log sheets were identified by participant number, study session, and date. A list linking participant number to participant name was stored securely by the investigators during the study and was destroyed once data collection and analysis was complete.

\section{Experimental Design and procedures}

A repeated measures $(2 \times 4)$ experimental approach was employed. Two administrations (i.e., tests) of the NCAT were performed per testing session. Each of the four testing sessions consisted of one of the following simulated environmental conditions:

1. baseline/ambient (BSL; $72 \pm 3^{\circ} \mathrm{F}, 50 \%$ humidity),

2. cold (CLD; $37 \pm 3^{\circ} \mathrm{F}$, target of $50 \%$ relative humidity),

3. hot/dry (HD; $113 \pm 3^{\circ} \mathrm{F}$, target of $20 \%$ relative humidity),

4. hot/humid $\left(\mathrm{HH} ; 104 \pm 3^{\circ} \mathrm{F}\right.$, target of $80 \%$ relative humidity),

The simulated environmental conditions were selected to induce thermal discomfort, but not result in any change in core temperature ${ }^{6-9}$ Wet-bulb globe temperatures (WBGT) indexes were calculated for each condition and used to determine the safe exposure limit for each condition via Table B2-A-2 from OPNAVINST 5100.19E (see Table 1 below) for Physical Exertion Level (PHEL) Curve I (i.e., light work). ${ }^{10}$

The participants performed at least five practice sessions of the DANA on a handheld computing device prior to testing (range 5-32 days) to familiarize with the assessment 
and to minimize the risk of any learning and/or practice effects. A breakdown of the practice and testing sessions is found in Table 1.

Table 1. Test conditions for neurocognitive testing.

\begin{tabular}{|c|c|c|c|}
\hline Session & Environmental condition & NCAT & $\begin{array}{c}\text { No. of } \\
\text { administrations }\end{array}$ \\
\hline Practice & - & DANA Brief & At least 5 \\
\hline \multirow{3}{*}{ Testing } & Baseline / ambient & DANA Brief & 2 \\
\cline { 2 - 4 } & Cold & DANA Brief & 2 \\
\cline { 2 - 4 } & Hot / dry & DANA Brief & 2 \\
\cline { 2 - 4 } & Hot / humid & DANA Brief & 2 \\
\hline
\end{tabular}

Note: NCAT = neurocognitive assessment tool; No. = number.

Four participants were each randomly assigned to one of four groups. The four members of the group were tested together during each environmental condition. Each group had at least a day between each testing session. All participants were required to wear minimal clothing (t-shirt, shorts, socks, and shoes). Light gloves and ear coverings were allowed for the cold environmental condition. Participants were required to refrain from alcohol for 24 hours and exercise for 12 hours prior to each testing session. Upon arrival at the laboratory, participants were encouraged to void their bladders. They were then weighed and instrumented for measurement of core temperature $\left(T_{c}\right)$, skin temperature $\left(T_{\text {sk }}\right)$, and heart rate $(H R)$.

A brief refresher was then given on how to complete the DANA test battery where participants were instructed to respond as rapidly and accurately as possible. Participants were instructed to complete two consecutive administrations with each administration lasting approximately 10-15 minutes. Participants were instructed to immediately start the second administration upon completion of the first and to sit quietly until all participants had completed.

After the procedure was fully explained, the participants entered the environmental chamber which was pre-set to one of the four simulated environmental conditions. Towels were supplied for comfort purposes. Once the environmental chamber doors where closed, participants sat patiently watching movies for 25 minutes prior to start of the first assessment. Thus, the total testing time was approximately 45-55 minutes for each environmental condition.

\section{Equipment and instrumentation}

The DANA is an NCAT that consists of a user interface, multiple automated cognitive tests, data management and reporting capabilities, and executive menu. The DANA battery was given on a Trimble NOMAD ${ }^{\circledR}$ handheld computing device using a stylus for consistency. The NOMAD runs a custom version of the Android Operating System and has a color 3.5 inch, pressure sensitive touch screen. It has been suggested that this 
format is optimally suited for tests of speed and accuracy as there is less variability in the test procedures than those encountered in standard desktop-based assessments. ${ }^{11}$

The DANA Brief Battery was used in this study to assess neurocognitive performance. The Brief Battery consists of six subtests: Simple Reaction Time (SRT), Code Substitution (CDS), Procedural Reaction Time (PRO), Spatial Processing (SPD), GoNo-Go (GNG), and Code Substitution Recall (CDD). Descriptions of these subtests can be found in Table 2. All tests are self-explanatory and begin with written instructions. To minimize learning and practice effects, test stimuli are generated at random and each test has built in practice trials embedded in every assessment prior to the actual test administration.

Table 2. DANA Brief Battery Subtest Descriptions

\begin{tabular}{|c|l|}
\hline Subtest & \multicolumn{1}{c|}{ Test Description } \\
\hline SRT & $\begin{array}{l}\text { This test measures pure reaction time and cognitive processing time. The participant taps on the location } \\
\text { of a bulls-eye as quickly as possible each time it appears. }\end{array}$ \\
\hline CDS & $\begin{array}{l}\text { This test assesses immediate memory and attention. A sequence of single symbol-digit pairs are shown } \\
\text { below a key, \& the participant indicates it matches the one in the key. }\end{array}$ \\
\hline PRO & $\begin{array}{l}\text { This test targets decision-making capabilities. One of the four numbers is displayed at a time for three sec } \\
\text { prior to the display of the next number. Participants are asked to differentiate whether the number that } \\
\text { appears on the screen is "2 or 3" or "4 or 5". }\end{array}$ \\
\hline SPD & $\begin{array}{l}\text { This test assesses spatial manipulation. Pairs of four-bar histograms are presented simultaneously on the } \\
\text { screen, one rotated 90 degrees from the other. The participant determines if the two histograms are the } \\
\text { same or different. }\end{array}$ \\
\hline GNG & $\begin{array}{l}\text { The test assesses speed and accuracy of targets, omissions, and commissions in order to derive a } \\
\text { sensitivity metric, as found in continuous performance tasks. A house is presented on the screen with } \\
\text { several windows. Either a "friend" (green) or "foe" (white) appears in the window. The respondent must } \\
\text { push a button only when a "foe" appears. }\end{array}$ \\
\hline CDD & $\begin{array}{l}\text { This test assesses short-term memory. After a delay, symbol-digit pairs are presented without the key. } \\
\text { The participant indicates whether or not the pairing was included in the key that was presented in the } \\
\text { earlier Code Substitution learning section. }\end{array}$ \\
\hline
\end{tabular}

Physiological and environmental data were continuously monitored during each testing session. The following instrumentation was used during each testing session:

- Trimble NOMAD with DANA Brief loaded;

- A T-8 data logger for recording $T_{c}$ and $T_{\text {sk }}$ data;

- $A T_{c}$ sensor inserted $15 \mathrm{~cm}$ beyond the anal sphincter,

- $T_{\text {sk }}$ sensors placed on the head, arm, pinky finger, foot, calf, thigh, and abdomen;

- Polar HR monitor strapped around the participant's thorax;

- Extech HT 30 Heat Stress WBGT Meter.

Mean $\mathrm{T}_{\text {sk }}$ was calculated from a 7-point measuring system using the following average weighting coefficients for each region. ${ }^{12}$ The formula used to calculate mean was:

Mean $T_{s k}=0.07($ head $)+0.14($ arm $)+0.07($ foot $)+0.13$ (calf $)+(0.19)$ thigh $+0.35($ abdomen $)$ 
All data, minus the WBGT Meter, were monitored and logged in LabVIEW in real time. These data were not used for data analysis purposes, but rather to monitor participant safety and to ensure that the environmental chamber was functioning properly.

\section{Data analysis}

Data processing. The technique we used to clean the dataset was a valid, yet extremely conservative, approach involving lower and upper thresholds or cutoffs to remove contaminant reaction times outside of the normal range of responses (i.e., outliers). Outliers can distort estimates of mean reaction time and standard deviation in reaction time as well as reduce the power of analyses of variance. ${ }^{13}$ The lower cut-off was used to remove 'fast' outliers that are considered anticipatory and too fast to be precise and/or deliberate responses. ${ }^{14}$ The upper cutoff was used to remove 'slow' outliers that were a result of lapses in concentration and was set at a point at which few responses would fall. ${ }^{14}$ Both the upper and lower cut-offs were set using normative data for military members for the ANAM ${ }^{15}$ The cut-offs have been used in previous studies and are presented in Table $3 .{ }^{11}$

Table 3. Data Cleaning Cutoffs for Reaction Times.

\begin{tabular}{|c|c|c|}
\hline Subtest & "Fast" & "Slow" \\
\hline SRT & \multirow{3}{*}{$\leq 150 \mathrm{~ms}$} & $900 \mathrm{~ms}$ \\
\hline PRO & & $2000 \mathrm{~ms}$ \\
\hline GNG & & $1500 \mathrm{~ms}$ \\
SPD & \multirow{3}{*}{$\leq 300 \mathrm{~ms}$} & $5000 \mathrm{~ms}$ \\
\hline CDS & $3000 \mathrm{~ms}$ \\
\hline CDD & & $4000 \mathrm{~ms}$ \\
\hline
\end{tabular}

Note: $\mathrm{ms}=$ milliseconds.

The remaining data were selected for further analysis and percent correct and throughput were calculated for each subtests:

$$
\begin{aligned}
& \% \text { correct }=\frac{\# \text { correct trials }}{\# \text { trials }} \\
& \text { Mean Throughput }=\frac{\% \text { correct }}{\text { Mean correct Reaction Time }}
\end{aligned}
$$

Participants with missing data as a result from termination of testing were removed from further analysis to ensure that partial data was not evaluated.

The normality of average throughput scores were statistically verified with both Lilliefors and Jarque-Bera tests $(p>0.05)$. Descriptive statistics were computed for mean throughput for each DANA subtest and each environmental condition.

Internal consistency. Data from both administrations in the baseline condition were combined to act as two parts or halves of a single administration for the internal consistency estimations. Cronbach's alpha ( $\alpha$ ) coefficient was used to measure the 
internal consistency (i.e., homogeneity) of the throughput scores for consecutive administrations for each of the DANA subtests within the baseline condition. The metric is calculated as follows:

$$
\propto=\frac{\mathrm{rk}}{([1+(\mathrm{k}-1) \mathrm{r}])}
$$

Whereas $\mathrm{k}$ is the number of items considered and $\mathrm{r}$ is the mean of the inter-item correlation. The size of $\alpha$ is determined by the number of items in the scale and mean inter-item correlation. An a greater than or equal to 0.80 was considered "excellent", values between 0.79 and 0.70 were considered "adequate", and those below 0.69 were to be considered poor. ${ }^{16}$

Subtest reliability. Data from the first assessment in each of the environmental conditions was used in the reliability estimations. The relative reliability across all four environmental conditions was estimated using a two-way random, average measures intra-class correlational coefficients (ICC) defined by:

$$
I C C_{(2, k)}=\frac{B M S-M S E}{B M S+\frac{k(W M S-M S E)}{n}}
$$

whereas BMS is the between-subjects mean square, MSE is the residual mean square error, WMS is the within-subjects mean square, $k$ is the number of data collection sessions (i.e., environmental conditions), $n$ is the number of subjects, all obtained from a $(1 \times 4)$ analysis of variance (ANOVA) with repeated measures with the environmental condition (4 levels) as the within-subjects variable. Univariate tests and simple effects tests were conducted to follow up significant main effects and interactions.

The ICC provides an estimate of relative reliability for the consistency of measurement. It is a ratio of the variance due to differences between the participants (the signal) and the total variability in the data (i.e., noise). Essentially, it is a unit-less measure of the test error in regard to between subject variability. Thus, it is reflective of the ability of a test to differentiate between different individuals. ${ }^{17}$ An ICC greater than or equal to 0.90 was considered "very high", values between 0.80 and 0.89 were considered "high", values between 0.70 and 0.79 were considered "adequate", values between 0.60 and 0.69 were considered "marginal", and those below 0.59 were to be considered poor. ${ }^{16} \mathrm{~A}$ value $\geq 0.90$ is recommended for clinical decision making and a value $\geq 0.70$ is conventionally seen as acceptable for research purposes. ${ }^{18}$

The standard error of the measurement (SEM), or 'typical error', was used to quantify absolute reliability. ${ }^{17,19}$ It carries the same units of measurement as the variable of interest and the interpretation of the SEM centers on the assessment of reliability within subjects. ${ }^{14}$ The SEM is the square root of the MSE found in the ICC ANOVA calculation $(S E M=\sqrt{M S E}) \cdot{ }^{17,19}$ 
Subtest reliability between each environmental condition and the baseline. Relative reliability was estimated using three two-way random, single measure ICC estimated from the results of three separate $(1 \times 2)$ analysis of variance (ANOVA) models with repeated measures with environmental condition (2 levels) as the within-subjects variable. Univariate tests and simple effects tests were conducted to follow up significant main effects and interactions. Absolute reliability or within-participant variation was estimated using the SEM.

\section{RESULTS}

A total of 16 male military personnel participated in this study. The mean age in years was 34 (standard deviation [SD] = 7.5). The mean height in centimeters was 178.1 (SD $=8.3$. . The mean body mass in kilograms was $88.9(S D=10.8)$. The mean time from the start of the first practice session to the completion of the fourth administration was 23.7 days $(\mathrm{SD}=5.6)$. The mean time to complete all four assessments was 15.53 days $(\mathrm{SD}=4.8)$ with an average of $3.9(\mathrm{SD}=1.2)$ days between each administration. Not all participants completed all four environmental conditions due to early termination of testing, equipment malfunction, or participant no shows. Thus, there were a total of 13 participants who had complete datasets. Descriptive statistics across environmental conditions are presented in Table 4.

Table 4. Descriptive statistics for DANA subtest throughput scores

\begin{tabular}{|l|l|c|c|c|c|}
\hline Subtest & $\boldsymbol{N}$ & $\boldsymbol{B S L}$ & $\boldsymbol{C L D}$ & $\boldsymbol{H D}$ & $\boldsymbol{H H}$ \\
\hline CDS & 13 & $53.49(7.60)$ & $54.42(6.09)$ & $57.18(6.25)$ & $55.62(10.29)$ \\
\hline CDD & 13 & $54.13(10.47)$ & $52.03(6.02)$ & $59.59(6.39)$ & $60.82(9.56)$ \\
\hline GNG & 13 & $58.26(1.69)$ & $56.97(3.04)$ & $57.61(2.37)$ & $57.79(1.83)$ \\
\hline PRO & 13 & $104.34(3.04)$ & $100.78(9.54)$ & $105.48(9.11)$ & $105.57(11.09)$ \\
\hline SPD & 13 & $40.84(7.80)$ & $40.93(11.86)$ & $41.40(8.27)$ & $41.56(9.45)$ \\
\hline SRT & 13 & $236.69(30.90)$ & $232.34(21.35)$ & $229.97(31.50)$ & $221.67(40.58)$ \\
\hline SRT2 & 13 & $239.36(27.70)$ & $225.16(25.44)$ & $224.19(35.40)$ & $220.98(38.05)$ \\
\hline
\end{tabular}

Note: All values are throughput scores represented as mean (standard deviation).

Internal consistency. As shown in Table 5, the mean internal consistency $(\alpha)$ of the DANA subtests within the baseline condition was found to be acceptable with mean values (i.e., across environmental conditions) ranging from poor for the CDD subtest (.21) to excellent for other five subtests (CDS, GNG, PRO, SPD, SRT, and SRT2). 
Table 5. DANA internal consistency and reliability metrics across environmental conditions.

\begin{tabular}{|l|c|c|c|c|c|}
\hline Subtest & $\boldsymbol{\alpha}$ & $\boldsymbol{I C C}$ & $\boldsymbol{I C C ~ 9 5 \% ~ C I}$ & $\boldsymbol{F}$ & SEM \\
\hline CDS & $.95^{a}$ & $.91^{b, c}$ & {$[.46-.89]$} & 1.98 & 4.07 \\
\hline CDD $^{\star}$ & .21 & $.74^{c}$ & {$[.14-.72]$} & 5.73 & 6.37 \\
\hline GNG & $.82^{a}$ & $.79^{c}$ & {$[.20-.76]$} & 1.79 & 1.44 \\
\hline PRO & $.94^{a}$ & $.90^{b, c}$ & {$[.45-.88]$} & 2.25 & 5.41 \\
\hline SPD & $.88^{a}$ & $.92^{b, c}$ & {$[.52-.90]$} & 0.07 & 4.86 \\
\hline SRT & $.87^{a}$ & $.88^{c}$ & {$[.40-.86]$} & 1.49 & 18.66 \\
\hline SRT2 & $.89^{a}$ & $.86^{c}$ & {$[.34-.83]$} & 2.14 & 20.13 \\
\hline
\end{tabular}

Note: ${ }^{*}=p$ value $\leq .007$ for significance after adjusting for multiple comparisons;

$a=$ meets acceptable or higher levels of internal consistency $(\geq .70)$;

$b=$ meets threshold for clinical decision making;

$c=$ meets acceptable or higher levels of reliability $(\geq .70)$.

Subtest reliability. As shown in Table 5 , the ICC values ranged from .74 to $.92(95 \% \mathrm{Cl}$ lower limits $\geq 0.14$ and upper limits $\leq 0.90)$. All of the subtests reached the conventionally accepted threshold of $\geq 0.70$, with CDS (0.91), PRO (0.90), and SPD (0.92) surpassing the very high mark. The subtest with the lowest ICC value, CDD (0.74), had significant difference between the environmental condition means $(F=5.75$, $p \leq .007)$. Pairwise comparisons revealed that mean for the cold environmental condition ( $M=52.03, S E=1.67)$ was significantly lower than the means for the HD $(\mathrm{M}=59.59, \mathrm{SE}=1.77)$ and $\mathrm{HH}(\mathrm{M}=60.82, \mathrm{SE}=2.65)$ environmental conditions. The SEM values ranged from a low of 1.44 for PRO to high of 20.13 for SRT2.

\section{DISCUSSION}

The purpose of this effort was to empirically examine specific psychometric properties of the DANA, an NCAT that was developed as a durable, portable, and field-hardened alternative to the ANAM. The internal consistency and the reliability, both relative and absolute, of the DANA were estimated from data collected from 16 active duty service members currently billeted at the Navy Experimental Diving Unit. The DANA Brief test battery was administered eight times in four different simulated field relevant environmental conditions over a period of 24 days. The primary findings were that the subtests within the DANA Brief test battery demonstrated adequate $(0.79)$ internal consistency and acceptable-to-excellent $(0.74$ to 0.92$)$ relative reliability across the four simulated environmental conditions.

Internal consistency (i.e., alpha coefficients) estimates reliability across test items in terms of item variance and covariance during a single administration of a test battery. The mean (i.e., across environmental conditions) internal consistency value for each subtest ranged from unacceptable-to-excellent with a mean of 0.79 with only the CDD subtest $(0.21)$ falling outside of the excellent range. The low alpha coefficient of the CDD was not unexpected as the participants completed two consecutive administrations of the DANA Brief test battery which may have resulted in proactive interference. ${ }^{20,21}$ Proactive interference can occur following repeated administrations of 
similar stimuli (e.g., digit-symbol pairings) as the stimuli learned in the first administration interferes with the recall of the second stimuli. ${ }^{22}$ Essentially, the individual gets confused about whether the digit-symbol pairing was presented during the second administration or the first administration.

The alpha coefficients presented here are very similar to previously reported values for the DANA subtests which ranged from adequate-to-excellent (mean $=0.78)^{5}$ and for values reported for the ANAM which ranged from poor-to-excellent (mean $=0.63$ ). ${ }^{21} \mathrm{~A}$ high degree of internal consistency is imperative for any NCAT as it provides confidence to a clinician and/or researcher in their ability to interpret the results as a reflection of the test items. ${ }^{20}$ Guidelines provided by Nunnally, considers: alpha coefficients $\geq 0.70$ to be adequate for a test in the early stages of development; alpha coefficients between 0.90 and 0.80 to be adequate for more developed tests such as the subtests found in the DANA and ANAM subtests; ${ }^{23}$ and alpha coefficients $>0.90$ to be indicative of a redundancy among items within a test. ${ }^{24}$ However, it is more likely the alpha coefficients $\geq 0.90$ in the current study were not a result of the redundancy of a single administration of the subtest, but simply the result of administering two test batteries consecutively, as all subtests were presented twice ${ }^{25}$ Additionally, an alpha coefficient $\geq 0.80$ can suggest good relative reliability because, as generalization of the split-half reliability, Cronbach's alpha estimates the likelihood of obtaining the same scores under multiple administrations. $^{26}$

Relative reliability has been argued to be the most important psychometric property of any NCAT. ${ }^{27}$ The DANA subtests ICCs ranged from acceptable-to-very high with a mean of 0.86 . More specifically, all of the subtests reached the conventionally accepted threshold for reliability of $\geq 0.70$. However, it has been suggested that this threshold is not strict enough for the purpose of individual decision making, and that an ICC of 0.90 or higher is necessary to provide useful information for clinical decision making. ${ }^{27}$ Only the CDS, PRO, and SPD subtests surpassed this threshold. The ICCs presented here were similar to previous reports for DANA subtests, which ranged from poor-to-very high with a mean of $0.85,{ }^{5}$ but slightly higher than those reported for ANAM subtest, which ranged from poor-to-high with a mean of $0.74 .{ }^{18} \mathrm{It}$ should be noted that in the previous reports, three of the DANA subtests reached the clinical decision making threshold, but none of the ANAM subtest did. ${ }^{5,18}$ One explanation why no ANAM subtest reached the 0.90 mark was the differences in the test-retest interval used in the studies. Dretsch et $\mathrm{al}^{18}$ used an interval of eight days which was twice the length of the interval used in the current study and eight times as long as the interval used by Lathan et al. ${ }^{5}$ The length of the test-retest interval is important as it has been reported that shorter intervals result in more stable tests results and higher relative reliability. ${ }^{29}$ However, it should be noted that if the intervals are too short (e.g., within the same day) it can result in decreased reliability due to possible practice effects. ${ }^{29}$

A technique that has been used to classify cognitive testing measures using both the internal consistency and relative reliability values was used to examine NCAT performance. Each subtest was sorted into one of two groups, either "most reliable" group or the "least reliable" group. A classification as "most reliable" indicates that 
clinicians should have the greatest confidence in the precision of scores from the tests. In order to be classified as "most reliable," the subtest had to have an alpha coefficient between 0.85 and 0.99 and an ICC between 0.75 and $0.99 .{ }^{30}$ In order to be classified as "least reliable," the subtest had to have an internal consistency value less than 0.80 and a relative reliability below $0.60 .{ }^{30}$ Using these criteria the current study and Lathan et al classified four DANA subtests (CDS, GNG, PRO, and SRT2) as being "most reliable" and no subtest as "least reliable." The only discrepancy between the two studies was that the current study classified the SPD and SRT2 subtest as "most reliable" whereas Lathan et al did not. Using data from Cernich et al, three ANAM subtests (STM and CPT) were classified as "least reliable" and no subtest as "most reliable."21

Although this study attempted to correct for many of the limitations with the previous report on the psychometric properties of the DANA, there were still limitations pertaining to the current study. The sample size was homogenous which limits the applicability to the general military or civilian population. A second limitation was the relatively short interval of $\sim 4$ days was used between test administrations as research has suggested that shorter test intervals result in higher reliability estimates. Thus, a longer interval of two weeks or a month may provide a more accurate estimate of reliability. A third limitation could be the presence of learning or practice effects. Practice effects may be represented by a change in test scores from one administration to the next even when no intervention is involved. However, there was no way to assess for the presence of any practice effects without a test-retest assessment performed in each environmental condition. Again it should be noted that in an attempt to control for practice effects stimuli in the DANA subtests are generated at random and each subtest has built in practice trials within each administration.

\section{CONCLUSIONS}

The DANA Brief test battery was administered to active duty personnel at the NEDU in four different simulated field relevant environmental conditions. The internal consistency and reliability was evaluated and it was found that DANA subtests demonstrated adequate internal consistency and acceptable-to-excellent relative reliability across the four simulated environmental conditions. Our findings add to the current body of research regarding the psychometric properties of the DANA; however, future research should focus on determining the validity, both construct and concurrent, of the DANA subtests against results of similar traditional clinical paper-and-pencil neuropsychological tests.

\section{ACKNOWLEDGEMENTS}

The authors thank the participants who volunteered as participants in this study. The authors also thank ND1 Gooch the task leader, whose tireless efforts were instrumental in this work. Funding is gratefully acknowledged from the BUMED M9 Program. 


\section{REFERENCES}

1. R. M. Reitan, D. Wolfson, The Halstead-Reitan Neuropsychological Test Battery: Theory and Clinical Interpretation. (Tucson, AZ: Neuropsychology Press, 1985).

2. D. M. Levinson, D. L. Reeves, "Monitoring Recovery from Traumatic Brain Injury Using the Automated Neuropsychological Assessment Metrics (ANAM V1.0)," Arch Clin Neuropsychol, Vol. 12, No. 2 (1997), pp. 155-166.

3. R. L. Coldren, M. L. Russell, R. V. Parish, M. Dretsch, M. P. Kelly, "The ANAM Lacks Utility as a Diagnostic or Screening Tool for Concussion More Than 10 Days Following Injury," Military Medicine, Vol. 177, No. 2 (2012), pp. 179-183.

4. J. L. Spira, F. J. Haran, J. W. Tsao, The Relationship between ANAM and DANA Military Battery Screening Tests in a Sample of Recently Deployed U.S. Marines. Unpublished manuscript.

5. C. Lathan, J. L. Spira, J. Bleiberg, J. Vice, J. W. Tsao, "Defense Automated Neurobehavioral Assessment (DANA)-Psychometric Properties of a New FieldDeployable Neurocognitive Assessment Tool," Mil Med, Vol. 178, No. 4 (2013), pp. 365-371.

6. J. N. Caldwell, L. Engelen, C. Van, "The Interaction of Body Armor, Low-Intensity Exercise, and Hot-Humid Conditions on Physiological Strain and Cognitive Function," Mil Med, Vol. 176, No. 5 (2011), pp. 448-493.

7. J. N. Caldwell, M. J. Patterson, N. A. Taylor, "Exertional Thermal Strain, Protective Clothing and Auxiliary Cooling in Dry Heat: Evidence for Physiological but not Cognitive Impairment," Eur J Appl Physiol, Vol. 112, No. 10 (2012), pp. 3597-3606.

8. G. E. Adam et al., "Hydration Effects on Cognitive Performance During Military Tasks in Temperate and Cold Environments ," Physiol Behav., Vol. 93, No. 4-5 (2008), pp. 748-756.

9. J.W. Castellini, R. Carter, G. Adam, S.N. Cheuvront, "Hypohydration Effects on Physical \& Cognitive Performance in Cold Environments," U.S. Army Research Institute of Environmental Medicine Report no. MISC 09-13 (2009).

10. U. S. Department of the Navy, Navy Safety and Occupational Health Program (SOH) Program Manual for Forces Afloat, Navy Operational Instruction 5100.19E Vol I: Safety and Occupational Health and Major Hazard-Specific Programs, May 2007.

11. J. L. Spira, C. E. Lathan, B. J., J. W. Tsao, "The Impact of Multiple Concussions on Emotional Distress, Post-Concussive Symptoms, and Neurocognitive Functioning in Active Duty United States Marines Independent of Combat Exposure or Emotional Distress," Journal of Neurotrauma, Vol. 31 (2014), pp. 1823-1834.

12. J. D. Hardy, E. F. Dubois, "The Technic of Measuring Radiation and Convection: One Figure," J Nutr, Vol. 15, No. 5 (1938), pp. 461-475.

13. R. Ratcliff, "Group reaction time distributions and an analysis of distribution statistics," Psychological Bulletin, Vol. 86 (1979), pp. 446-461.

14. R. Ratcliff, "Methods for dealing with reaction time outliers," Psychological Bulletin, Vol. 114, (1993) pp. 510-532. 
15. A.S. Vincent, T. Roebuck-Spencer, K. Gillard, R. Schledgel, "Automated Neuropsychological Assessment Metrics (v4) Traumatic Brain Injury Battery: Military Normative Data," Mil Med, Vol 177, No. 3 (2012), pp. 256-269.

16. M. D. Lezak, D. B. Howieson, E. D. Bigler, D. Tranel, Neuropsychological Assessment, Vol. 5 (New York: Oxford University Press, 2012).

17. J. P. Weir, "Quantifying Test-Retest Reliability Using the Intraclass Correlation Coefficient and the Sem," Journal of Strength and Conditioning Research, Vol. 19, No. 1 (2005), pp. 231-240.

18. M. Dretsch, R. Parish, M. Kelly, R. Coldren, M. Russell, "Eight-Day Temporal Stability of the Automated Neuropsychological Assessment Metric (ANAM) in a Deployment Environment," Appl Neuropsychol Adult, Vol. 22, No. 4, (2015), pp. 304-310.

19. W. G. Hopkins, "Measures of Reliability in Sports Medicine and Science," Sports Med, Vol. 30, No. 1 (2000), pp. 1-15.

20. D. L. Streiner, "Starting at the Begining: An Introduction to Coefficient Alpha and Internal Consistency," Journal of Personality Assessment, Vol. 80, No. 1 (2010), pp. 99-103.

21. A. Cernich, D. Reeves, W. Sun, J. Bleiberg, "Automated Neuropsychological Assessment Metrics Sports Medicine Battery," Arch Clin Neuropsychol, Vol. 22 Suppl 1 (2007), pp. S101-114.

22. C. E. Osgood, "The Similarity Paradox in Human Learning: A Resolution," Psychological Review, Vol. 56, (1949), pp. 132-143.

23. J. C. Nunnally, I. H. Bernstein, J. M. F. Berge, "Psychometric Theory" in Psychometric Theory (New York: McGraw Hill,1967).

24. S. Ferketich, "Focus on Psychometrics. Internal Consistency Estimates of Reliability," Res Nurs Health, Vol. 13, No. 6 (1990), pp. 437-440.

25. M. Llorente, A. J. Amado, R. G. Voigt, M. C. Berretta, "Internal Consistency, Temporal Stability, and Reproducibility of Individual Index Scores of the Test of Variables of Attention in Children with Attention-Deficits," Arch Clin Neuropsychol. Vol. 16, No. 6 (2001), pp. 535-546.

26. R. C. Gur et al., "A Cognitive Neuroscience-Based Computerized Battery for Efficient Measurement of Individual Differences: Standardization and Initial Construct Validation," J Neurosci Methods, Vol. 187, No. 2 (2010), pp. 254-262.

27. C. Randolph, M. McCrea, W. B. Barr, "Is Neuropsychological Testing Useful in the Management of Sport-Related Concussion?," Journal of Athletic Training, Vol. 40, No. 3 (2005), pp. 139-152.

28. S. P. Broglio, M. S. Ferrara, S. N. Macciocchi, T. A. Baumgartner, R. Elliott, "Test-Retest Reliability of Computerized Concussion Assessment Programs," Journal of Athletic Training, Vol. 42, No. 4 (2007), pp. 509-514.

29. A. Collie, P. Maruff, D. G. Darby, M. McStephen, "The Effects of Practice on the Cognitive Test Performance of Neurologically Normal Individuals Assessed at Brief Test-Test Intervals.," Journal of the International Neuropsychological Society, Vol. 9, (2003), pp. 419-428.

30. G. L. Iverson, "Interpreting Change on the WAIS-IIIMMS-III in Clinical Samples," Arch Clin Neuropsychol, Vol. 16, No. 2 (2001), pp. 183-191. 


\section{APPENDIX A}

\section{Standard Operating Procedure for the Defense Automated Neurobehavioral Assessment (DANA) v1.5.3 Application on the Samsung GALAXY Note ${ }^{\circledR}$ v10.1}

The purpose of this Standard Operating Procedure (SOP) is to provide clear and detailed instructions on how to operate and utilize the DANA v1.5.3 app that has been pre-installed onto a Samsung GALAXY Note ${ }^{\circledR}$ V10.1. These procedures are used to set up and administer the DANA cognitive tests to potential subjects. These procedures are also used to transfer screening data to a Data Management PC for analysis.

The minimum requirements for the Data management PC are as follows:

- Operating system: Windows XP (Service Pack 2), Windows 7, or Mac OS X,

- RAM: 3GB,

- Storage: 200MB free,

- Processor: X86 (intel or AMD), 2GHz,

- Ports: 1 USB 1.0,

- Display: $1024 \times 768$.

The following SOP requires that the following applications/packages/files be installed on the Data Management PC using the DANA v.1.5.3 Quick Reference Guide Section B.

- Microsoft Visual C++ package (Windows XP only).

o Launch vcredistx86 (20110).exe or vcredistx64 (20110).exe for 32-bit Windows XP and 64-bit Windows XP respectively.

- The Samsung Android USB Driver for Windows

o Visit the following website to download the file: http://developer.samsung.com/android/tools-sdks/Samsung-Andorid-USBDriver-for-Windows

- Java JDK (x86 or 32-bit version)

o Visit the following website to download the file: http://www.oracle.com/technetwork/java/javase/downloads/jdk7downloads-1880260.html

- Java Cryptography Extension (JCE) Unlimited Strength Jurisdiction Policy files

o Visit the following website to download the zipped file: http://www.oracle.com/technetwork/java/javase/downloads/jce-7download-432124.html

o Navigate to the following directory: C:/Program Files/Java.

o Open the most recently updated $j r e$ and/or jdk folder.

o Open the lib folder then open the security folder. 
o Copy the local_policy.jar and US_export_policy.jar files located in the unzipped DANA install filers to the security folder above.

- Android SDK

o Visit the following website to download the file: http://developer.android.com/sdk/index.html

o At the site select Download for other platforms,

o Select the Windows Installer option (installer_r22.0.1-windows.exe) of the SDK Tools only section of the table to install.

- Android SDK Platform Tools

o The following packages will need to be installed from the Android SDK Manager:

- Android SDK Platform-tools,

- Android SDK Tools,

- Android SDK Build-tools,

- Google USB Driver.

- DANA Data Manager v1.1.11

o Launch Install DANA Data Manager.exe file from the unzipped DNAN install filers.

DANA is programmed to run in Android, therefore the mobile computer, Samsung GALAXY Note ${ }^{\circledR}$ V10.1, is a sufficient device for the purpose of this SOP. This SOP requires that the DANA application and test batteries already be installed on the Notebook and all Administrators be created and added to the Notebook using the DANA v.1.5.3 Quick Reference Guide Section C. Administrators may only be created and added once during initial setup and cannot be added at a later time without uninstalling DANA and erasing the data from the Notebook. A USB cable and Administrator rights (password protected) are also required for transferring data from the mobile computer to the Data Management PC, opening datasets on the Data Management PC, and setting up the mobile computer.

Before administering a screening, it is highly suggested that the Notebook settings be set to the following:

- Connections Tab

o Turn Wi-Fi off.

o Turn Bluetooth off.

o Check airplane mode.

o Location Services,

- Uncheck Access to my location.

o Turn Nearby Services off. 
- Device Tab

o Sound

- Set Volume to lowest settings,

- Set Vibration Intensity to highest settings,

- Uncheck and silent all Notifications and System sounds.

o Display

- Set Brightness to highest setting,

- Set screen timeout to highest setting,

- Set Touch key light duration to Always off,

- Set Daydream to Activate screen saver off.

- Controls

o Turn Voice control off.

o S Pen

- Check Turn off pen detection,

- Turn pointer off,

- Turn all Air view settings off.

o Turn all Motion control off.

o Turn all Smart screen settings off.

- General

o Turn all Backup and reset settings off

o Developer options

- Turn USB debugging on,

- Turn all other settings off.

\section{PROCEDURES}

\section{CREATE A NEW EXAMINER}

1. Turn on Notebook by pressing and holding the top left button.

2. Select the Apps Tray icon on the bottom right corner of the screen to view all apps downloaded on the Notebook.

3. Launch DANA by selecting the App icon (Figure 1).

4. At the Login screen, press the menu button to the left of the Home button on the Notebook to select what information requires editing, Create Examiner or Manage Device (Figure 2).

a. If Create Examiner is selected, enter the Examiner Name, New Password, Confirmed New Password, and Login Password Hint.

i. Select Save to save the changes made to the Examiner.

ii. Select View administrators with access to this examiner to generate a list of personnel that are authorized to use the data. 
1. Enter the examiner username and password that was established during the application process when prompted to by the Log in screen (Figure 2).

a. If the examiner credentials are incorrect the screen will display Wrong name or password at the bottom of the screen.

b. If a screen timeout has occurred while using the app, the login screen will be displayed after reactivating the Notebook. The login screen will display DANA has restarted due to loss of focus at the bottom of the screen.

c. The user must sign in again every time the app is closed and reopened.

2. Select an existing subject or create a new subject by selecting Add a New Person (Figure 3).

a. Only the Name field is required in order to create new subject. The other fields (Social Security Number, Unit, and Injured) are optional.

b. When selecting the injured box the screen prompts the user to select a time and date of injury using a calendar and 24 hour clock (Figure 4).

c. Once the subject's information has been entered select Create New Person (Figure 3).

3. Select the test battery (DANA Rapid (1.1), DANA Brief [NO S](1.1), DANA Standard [NO S](2.0)) and select Start New Screening (Figure 5 and 6).

a. Hand the Notebook to the subject to complete the screening. The screen will provide directions for the subject.

b. When the screening is complete the subject will be prompted to return the Notebook to the examiner (Figure 7).

4. Select Screening Complete at the bottom of the screen and the examiner will automatically be logged out for data security.

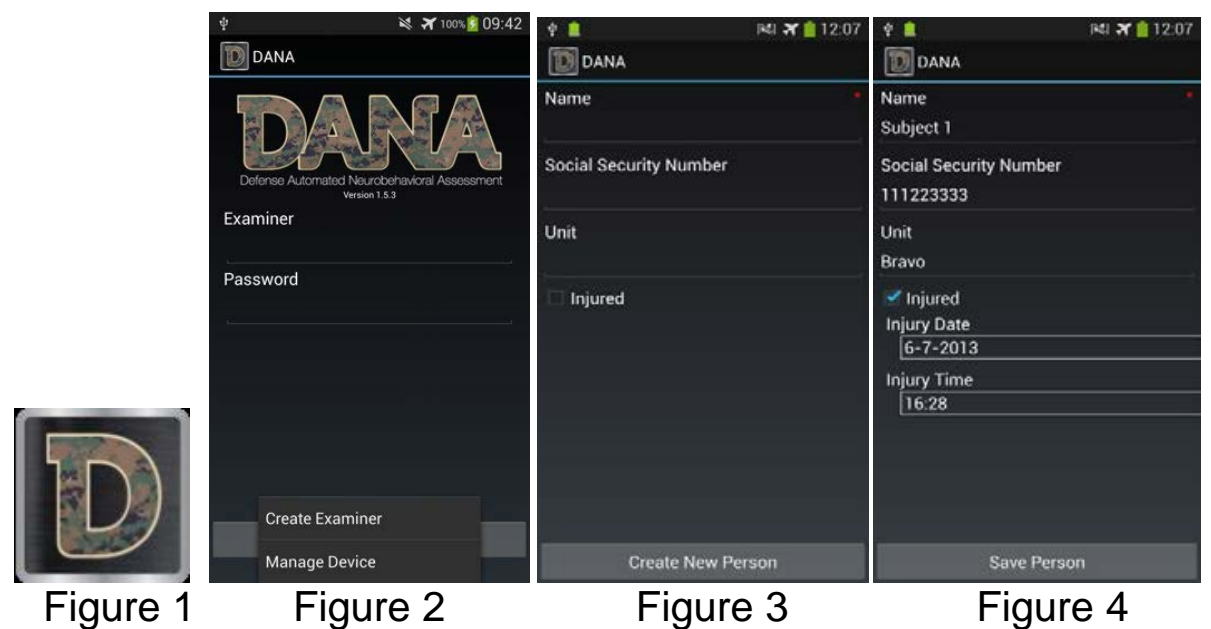




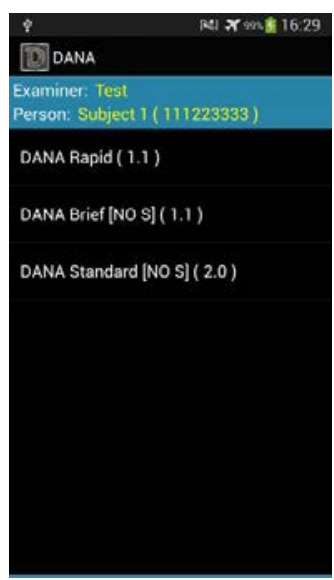

Figure 5



Figure 6

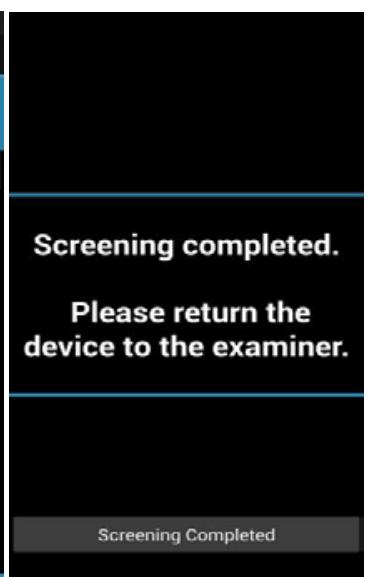

Figure 7

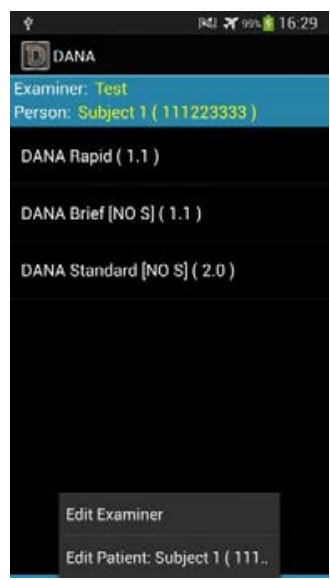

Figure 8

\section{EDIT EXAMINER AND SUBJECT INFORMATION}

1. After entering the examiner username and password, select the subject whose information requires editing.

2. Press the menu button to the left of the Home button on the Notebook to select what information requires editing, Edit Examiner or Edit Patient: Subject Name (Figure 8).

a. If Edit Examiner is selected, the program will allow the user to change the Examiner name and password as long as the current password can be provided and the new password can be confirmed.

i. Select Save to save the changes made to the Examiner.

ii. Select View administrators with access to this examiner to generate a list of personnel that are authorized to use the examiner data.

b. If Edit Patient: Subject Name is selected, the program will return the user to the subject information page created in step 5 of ADMINISTERING A SCREENING (Figure 4). This will allow the user to make changes to the subject's Name, Social Security Number, Unit, or Injured information.

i. Select Save Person to save the changes made to the subject's information (Figure 4).

\section{ABORTED SCREENINGS}

A screening is aborted by pressing the home or power button on the Notebook during a screening. A subject with any aborted screening will have a red warning symbol next to their name, test, and screening that was aborted.

1. Select the aborted subject, test, and screening (Figure 9, 10, and 11).

2. If no sections of the screening have been completed before the screening was aborted, select Discard Screening or Resume Screening at the bottom of the screen (Figure 12). 
a. If Discard Screening is selected, the program will ask Discard this screening? Select Yes to delete from memory and No to return back to the aborted screening page.

b. If Resume Screening is selected, the subject will restart the screening process.

3. If sections of the screening have been completed before the screening was aborted, select Convert to Final Result, Resume Screening, or Resume Screening and Repeat Last Completed Section (Figure 13).

a. If Convert to Final Result is selected, a report will be generated based on the section or sections that were completed.

b. If Resume Screening is selected, the subject will start screening after the last completed section.

c. If Resume Screening and Repeat Last Completed Section is selected, the subject will repeat screening of the section that was completed before the screening was aborted.

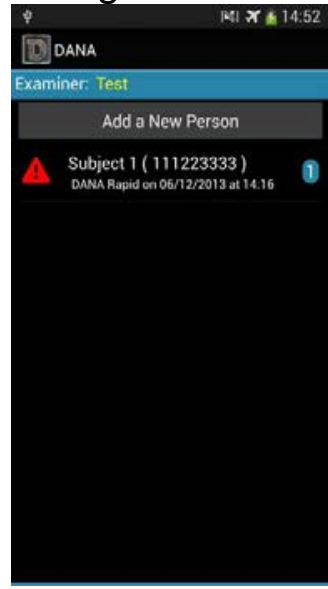

Figure 9

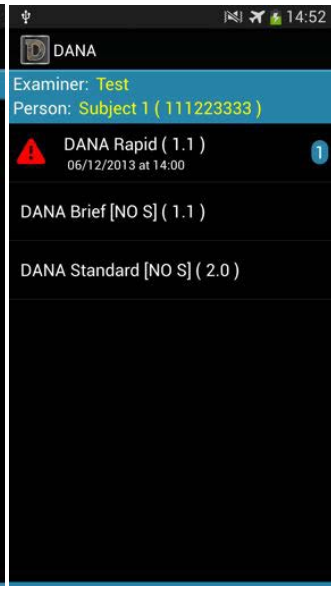

Figure 10

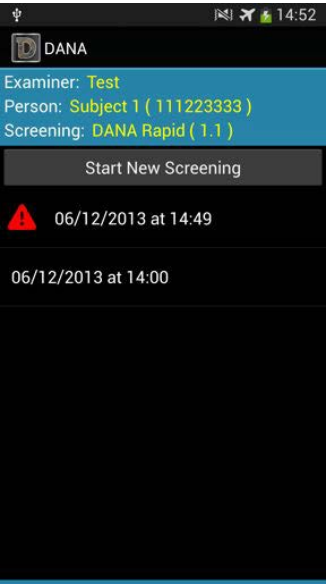

Figure 11

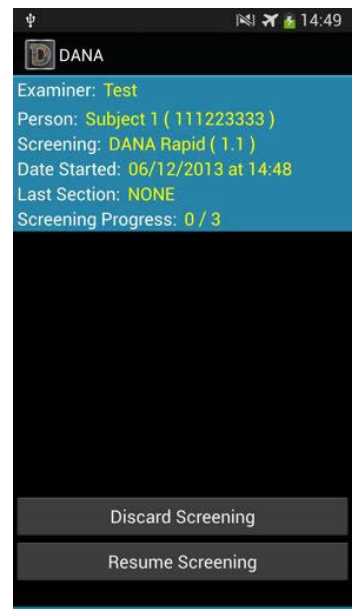

Figure 12

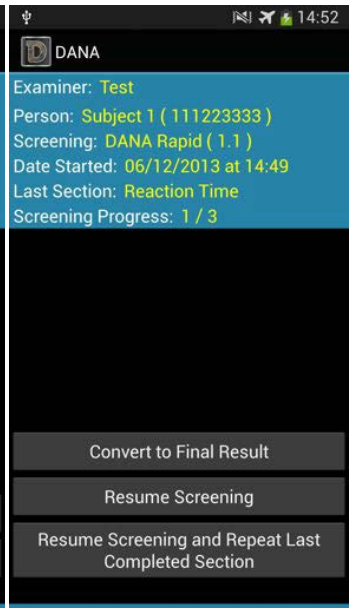

Figure 13 


\section{VIEWING RESULTS ON NOTEBOOK}

1. Complete screening as described in step 7 of ADMINISTERING A SCREENING.

2. Enter examiner password if viewing results directly after the completion of a screening.

a. If viewing results after closing DANA, log in as described in steps 3 and 4 of ADMINISTERING A SCREENING.

3. Select the individual screening to view and generate the Report Summary screen if viewing results directly after the completion of a screening (Figure 14).

a. If viewing results after closing DANA, select desired subject, test battery, and individual screening.

4. Press the menu button to the left of the Home button on the Notebook to select sections of the report.

a. If selecting a screening from a DANA Rapid battery test, the sections are Summary and Results and Cognitive Section Details (Figure 15).

i. If Summary and Results is selected, the program will return the user to the Report Summary screen (Figure 14).

ii. If Cognitive Section Details is selected, the program will ask which section details the user would like to view Reaction Time, Procedural Reaction Time, or Go No Go (Figure 16).

b. If selecting a screening from a DANA Brief [NO S] battery test, the sections are Summary and Result, Psychological Section Details and Cognitive Section Details.

i. If Summary and Results is selected, the program will return the user to the Report Summary screen (Figure 14).

ii. If Psychological Section Details is selected, the program will ask which section details the user would like to view PHQ-8, PCPTSD Survey, or ISI Survey.

iii. If Cognitive Section Details is selected, the program will ask which section details the user would like to view Reaction Time, Code Sub [Learning], Procedural Reaction Time, Spatial Processing, Go No Go, Code Sub [Recall], or Reaction Time.

c. If selecting a screening from a DANA Standard [NO S] battery test, the sections are Summary and Result, Psychological Section Details and Cognitive Section Details.

i. If Summary and Results is selected, the program will return the user to the Report Summary screen (Figure 14).

ii. If Psychological Section Details is selected, the program will ask which section details the user would like to view CES Survey, PHQ8, PSQI Survey, PCLM Survey, or DSI [NO S].

iii. If Cognitive Section Details is selected, the program will ask which section details the user would like to view Reaction Time, Code Sub [Learning], Procedural Reaction Time, Spatial Processing, Go No Go, Code Sub [Recall], Matching To Sample or Reaction Time. 
d. Note that if Aborted screenings were converted into final results as in step 3 of $A B O R T E D$ SCREENINGS, only the sections completed will have result details.



Figure 14

Figure 15

Figure 16

\section{TRANSFER DATA TO DATA MANAGEMENT PC}

1. Turn on Notebook by pressing and holding the top left button.

2. Plug in Notebook into the Data Management PC using the USB cable provided.

3. Launch the DANA Data Manager (DDM) on the Data Management PC and select Manage Administrators (Figure 17).

4. Select Open Administrator from the DANA Administrator window (Figure 18).

5. Locate and select the Administrator Key Store file (.DANAKeyStore) created during set up and creation of Administrators and select Open.

6. Enter the Administrator password into the Administrator password window and select $O K$.

a. If an Administrator has been successfully opened, the Administrator should appear in the DANA Administrator Manager window under Current Administrators. Close the DANA Administrator Manager window.

b. If an Administrator has not been successfully opened, a pop-up window will appear displaying Could not open administrator. Close the DDM window and DANA Administrator Manager window and repeat steps 3 through 6.

7. Launch DANA as described in steps 2 through 4 of CREATE A NEW EXAMINER. 
a. If Manage Device is selected from the menu options of the login screen the screen will display Waiting for connection from host computer (Figure 19).

b. If the menu window does not display, press the back button to refresh the login screen and repeat step 7.

8. Select Manage Device / Download Data in the DDM window on the Data Management PC (Figure 17).

a. If the Data Management PC successfully connects to the mobile device, the screen on the Notebook will display Management system active and the Manage Device / Import Data window will appear displaying the examiners that the Administrator has access to (Figure 20).

b. If the Data Management PC does not successfully connect to the mobile device see the TROUBLESHOOTING section of this SOP for solutions.

9. Select the desired Examiners whose data requires transferring or select Select All Examiners in the Manage Device / Import Data window and select Transfer Data For Selected Examiners (Figure 20).

10. To delete data on device after transfer, uncheck the box that displays Keep data on device after transfer (Figure 20).

11. Navigate through the folders of the Data Management PC to select the desired location to save the transferred data in the Data Transfer Destination window and select Open.

12. A Message window will appear displaying Transfer Completed. Select OK.

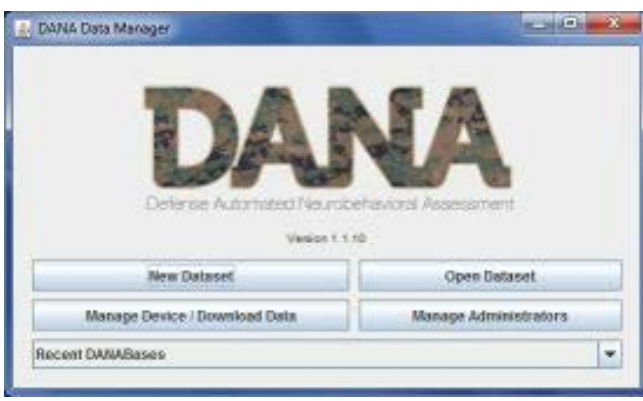

Figure 17

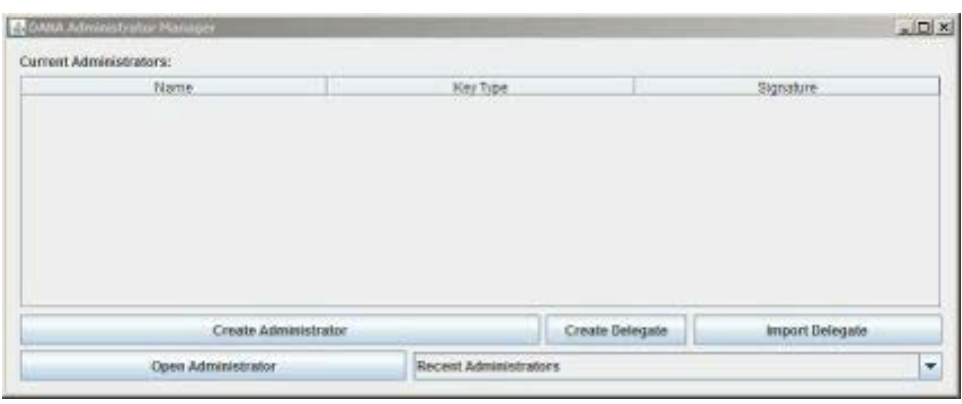

Figure 18 


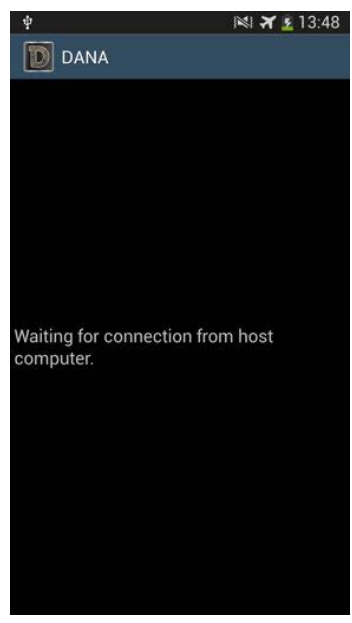

Figure 19

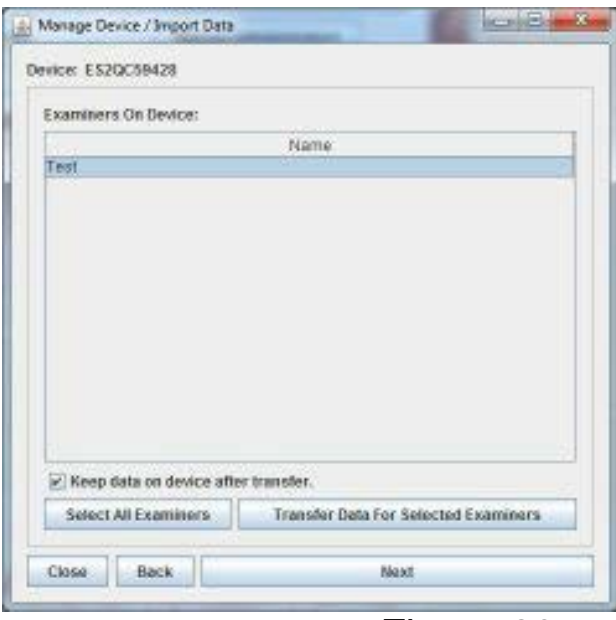

Figure 20

VIEWING RESULTS ON THE DATA MANAGEMENT PC

1. Launch the DDM on the Data Management PC and select Open Dataset (Figure 17).

2. Navigate through the folders to locate the DANABASE file (danaBase) that was saved in step 11 of TRANSFER DATA TO DATA MANAGEMENT PC in the Choose DANA Base window.

3. Select the desired file and select Open. Files are named with the device number, date and time that the information was transferred to the Data Management PC as default.

4. A password may or may not be required to view the results.

a. If a password is required, enter the password for the Examiner or open with an Administrator.

i. To open with Examiner password, enter the password for the Examiner under whom the data was collected and select Open (Figure 21).

ii. To open with an Administrator, select Manage Administrators and complete steps 4 through 6 of TRANSFER DATA TO DATA MANAGEMENT PC. After the Administrator has been opened, close the DANA Administrator Manager window and select Open with Administrator in the password window (Figure 21).

b. If a password is not required, an Administrator with access to the Examiner results has already been opened and the DANA Viewer window will open (Figure 22).

5. There are two view options for viewing the data under the examiner selected Tree and Table. 
a. The default view option is Tree with two folders, Screenings and Patients displayed in the left panel (Figure 22).

i. To select data by screening, expand the following folders in order by double clicking: Screenings $\rightarrow$ Test Battery $\rightarrow$ Patients $\rightarrow$ Patient Name (Figure 22)

ii. To select data by patient, expand the following folders in order by double clicking: Patients $\rightarrow$ Patient Name $\rightarrow$ Screenings $\rightarrow$ Test Battery (Figure 22).

b. To view data in Table format, select View from the top left menu and check as Table.

i. The Table format gives the name of the subject and date of screening. The highlighted rows of the table are the test battery and subtests (Figure 23).

6. The screenings are labeled by date and time the test was administered. Double click on the screening to view the report displayed in the right panel.

7. There are two format options for the report Full and Basic.

a. The default format option is Full with a detailed report on the screening. To expand the sections and subsections of Battery Test click next to the little black triangles (Figure 24).

b. To view results in Basic format, select Format the top left menu and check Basic (Figure 25).

8. There are three options to view other DANABase files from the DANA Viewer window. To open an additional DANABase file select File from the top left menu and select New DANABase, Open DANABase, Open Recent DANABase, or Import Data from local DANABases.

a. If New DANABase or Open DANABase are selected, a Choose DANA Base window will appear. Repeat steps 2 through 4 to open the desired DANABase file.

b. If Open Recent DANABase is selected, a list or DANABase files that have been recently opened will appear. Select the desired DANABase file to be opened from the list.

C. If Import Data from local DANABases is selected, a password for DANABase to import is required. Enter the password and select Import DANABase. Select the desired DANA file(s) to import and select Open (Figure 26). 


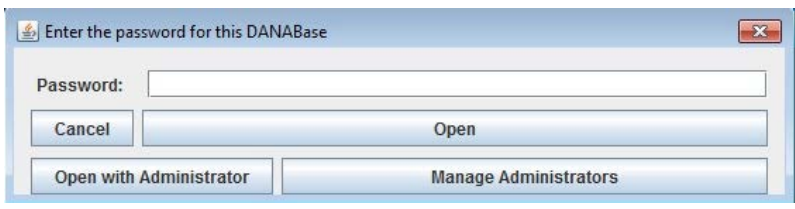

Figure 21

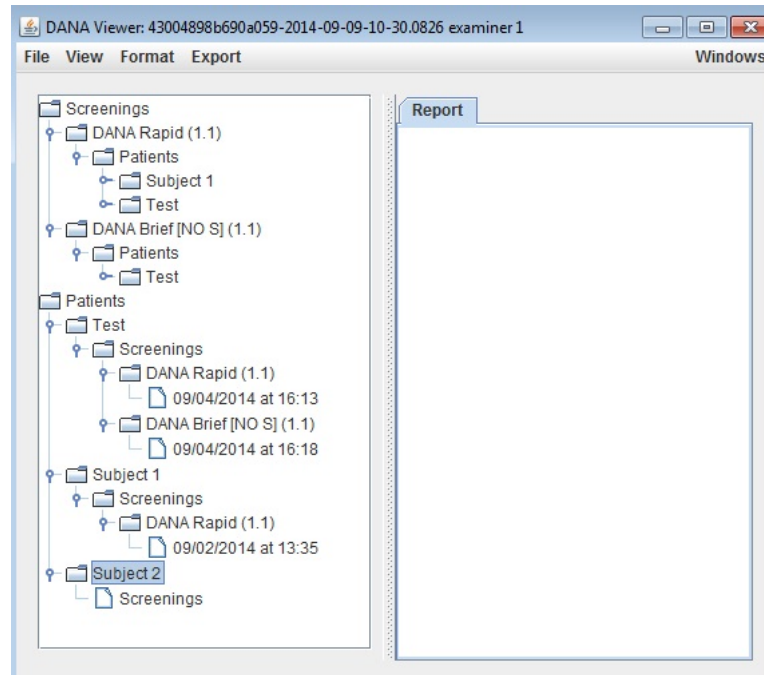

Figure 22

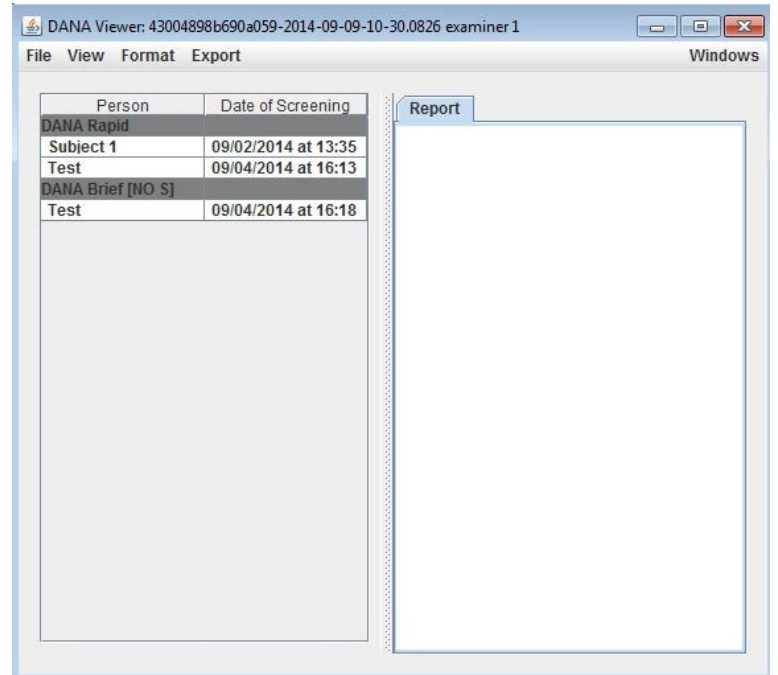

Figure 23

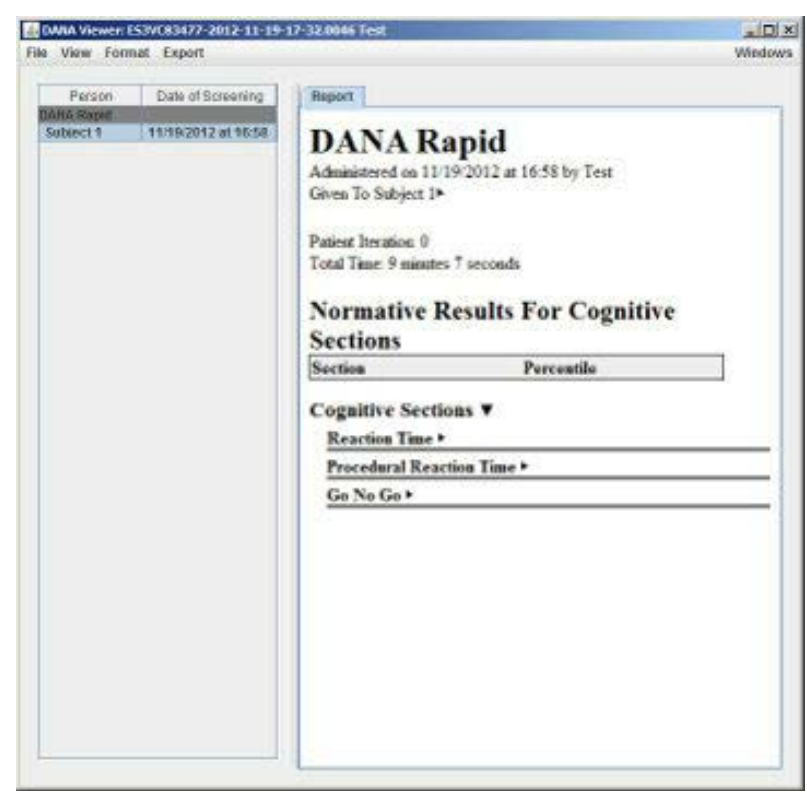

Figure 24

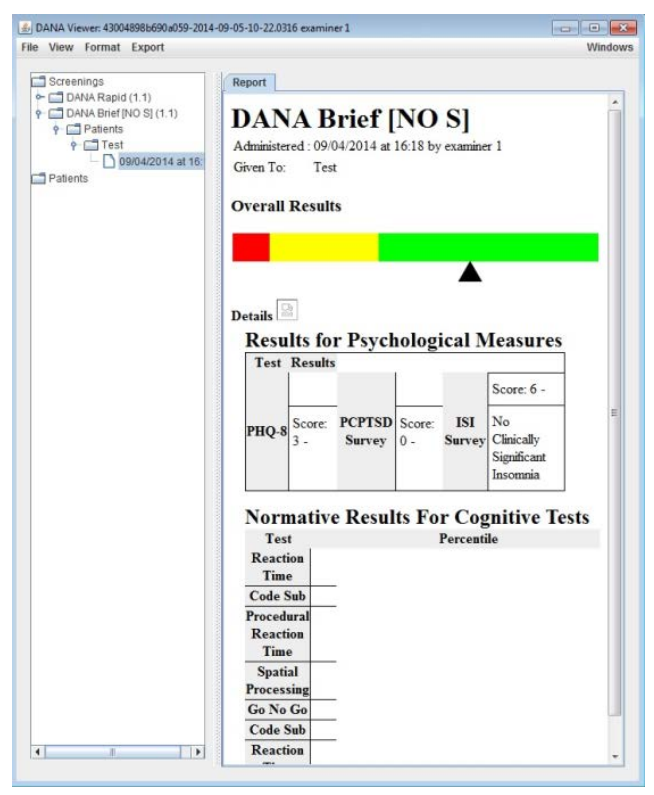

Figure 25 


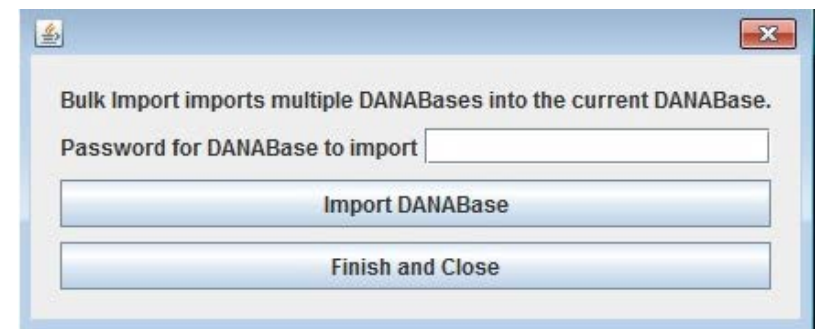

Figure 26

\section{EXPORT TRANSFERRED DATA}

1. Complete steps 1 through 6 of TRANSFER DATA TO THE DATA MANAGEMENT PC for the desired screening to be exported (data must already be transferred to the Data Management PC).

2. Once a screening has been selected, select Export from the top left menu and choose an export option.

a. If export option $X M L$ is selected, one $X M L$ file per test per subject will be generated including cognitive test data, psychological test data, and trialby-trial data.

b. If export option Full Report is selected, one HTML file per test per subject will be generated including cognitive test data, psychological test data, and trial-by-trial data.

c. If export option PDF Report is selected, one PDF file per test per subject will be generated including cognitive test data, psychological test data, and trial-by-trial data.

d. If export option Test Statistics is selected, 3 to 7 CSV files per cognitive test will be generated including cognitive test data.

e. If export option Test Responses is selected, 3 to 7 CSV files per cognitive test will be generated including cognitive test data and trial-by-trial data.

f. If export option Single Row per Subject is selected, one CSV file per subject will be generated including cognitive test data a psychological test data (only scores).

g. If export option Demographics is selected, one CSV file will be generated including trial-by-trial data taken from the demographics survey.

h. If export option Extended Format - User UUID is selected, 7 to $25 \mathrm{CSV}$ files ( 2 files per test plus 1 to 3 files with overall screening information) will be generated including cognitive test data, psychological test data, and trial-by-trial data.

i. If export option Extended Format is selected, 4 to 19 CSV files (1 to 2 files per test plus 1 to 3 files with overall screening information) will be generated including cognitive test data, psychological test data, and trialby-trial data. 
j. If export option Finger Tapping Test Export is selected, 2 CSV files will be generated including cognitive test data (only responses to finger tapping test).

k. If export option Raw Balance Data is selected, 5 CSV files per stance will be generated from data collected during the Balance Test.

I. If export option Raw Data is selected, 13 to 22 CSV files will be generated including cognitive test data, psychological test data, and trial-by-trial data.

3. To add a file to export, highlight the desired screening in the table of the left panel and select Add to Export. The screening will be moved over to the Export tab of the right panel under Items in Export (Figure 27).

4. To remove a screening from the Items in Export list, highlight the desired screening and select Remove Item located in the Export tab of the right panel.

5. Configuration options are available for export options Extended Format - User UUID and Extended Format. To select the configuration option, check Export Test Meta Data (Figure 28).

6. Once the desired screening(s) for export have been selected into the Items in Export list, select Export at the bottom of the Export tab in the DANA Viewer window (Figure 27).

7. Navigate through the folders in the Select Export Destination window to export the screenings to and select Open.

8. A message window will appear stating if the export was successful or not.

a. If the export was successful, the message will display Export completed $O K$; select $O K$.

b. If the export was unsuccessful, the message will display Export failed or was canceled; select $O K$.

i. Select Close at the bottom of the Export tab to close the tab.

Repeat step 2 to select an export option that is more suitable for the type of battery test and screening that is being exported. For more details on the export options see Section D-6 of DANA v1.5.3 Quick Reference Guide. 


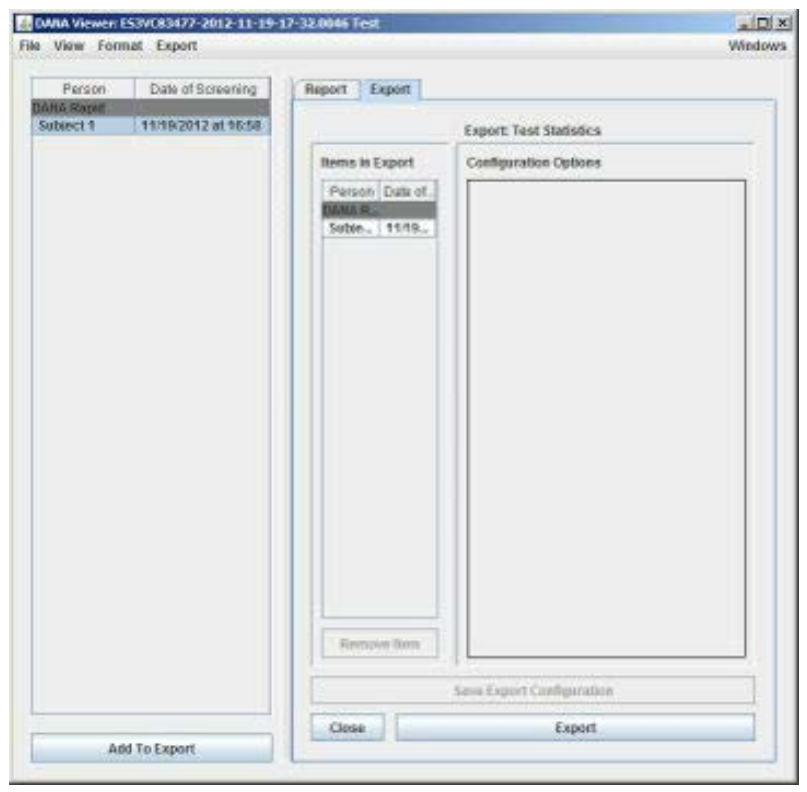

Figure 27

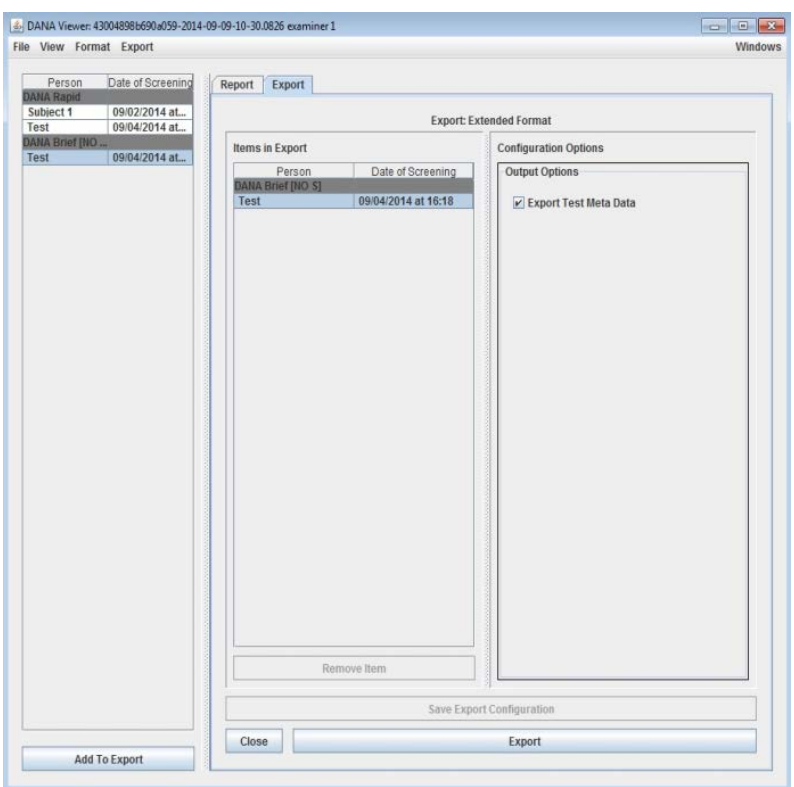

Figure 28

\section{QUALITY CONTROL:}

BACKUP TRANSFERRED DATA

The location selected for the backup will have a new folder with the device's serial number as the name. Within this folder is a compressed zipped file labeled with the date and time in which the backup was completed. The compressed file contains Data Base files, HTML Documents, XML Documents and HD files.

1. Complete steps 1 through 8 of TRANSFER DATA TO THE DATA MANAGEMENT PC for the desired data to be backed up.

2. Select the examiner(s) for the given Administrator whose data requires a backup or select Select All Examiners in the Manage Device / Import Data window and select Next (Figure 20).

3. In the next Manage Device / Import Data window select Create Device Backup (Figure 29).

4. Navigate through the folders in the Backup Destination window to backup the data from the selected examiners to and select Open.

5. A message window will appear stating if the backup was successful or not

a. If the backup was successful, a message window will display Backup Completed, connection will close. Select Ok to return to the Manage Device / Import Data window. 
6. The connection between the Notebook and the DDM will be lost at the completion of the backup.

TROUBLESHOOTING

The DDM is unable to recognize the Notebook as a mobile device and/or connection to the mobile device was unsuccessful. Connection can be lost if the Data Management PC is set to hibernate after a period of inactivity, the DDM window closes Utilize the following checklist to ensure a successful connection between the Nomad and the DDM.

Verify that the versions of DANA, the DDM, and Android are compatible with one another. For the purpose of this SOP the following compatible versions were used: DANA v.1.5.3, DDM v1.1.11, and Android v4.3. To verify the compatibility of other versions see Section E of DANA v1.5.3 Quick Reference Guide.

0 The version of DANA can be checked by launching DANA on the Notebook. The version is displayed below the logo on the login screen (Figure 2).

o The version of DDM can be checked by launching the DDM on the Data management PC. The version is displayed below the DANA logo in the Dana Data Manager window (Figure 17).

o The version of Android can be checked on the Notebook by going to the settings app and selecting About device at the bottom of the settings list on the General tab.

Verify that the correct USB cable provided is securely connected to both the Data Management PC and Notebook.

o Unplug the USB cable from the Data Management PC and plug back in or use a different USB cable.

Verify the settings configuration listed in Section E Equipment and Supplies for the Notebook.

0 Verify that the screen timeout is at the highest setting. The device will not connect if the screen times out before a connection had been made.

o Verify that the USB debugging is enabled.

Verify the installations required in Section E Equipment and Supplies for the Data Management PC.

o Verify that the Android SDK packages Android SDK Tools, Android SDK Platform-tools, Android SDK Build-tools, and Google USB Driver are installed and up to date.

- If these packages display Not installed in the status column of the Android SDK Manager window, check the packages that require installation and select Install_ packages (Figure 30).

- If these packages display Update available in the status column of the Android SDK Manager window, check the packages that require installation and select Update packages. 
o Verify that the correct mobile computer driver is installed properly on the Data Management PC. An appropriate driver for the Notebook is the Samsung Android USB Driver for Windows.

- Without the proper USB driver installed, the Data Management PC will be unable to recognize the Nomad device. This is characterized by the following:

- The Manage Device / Import Data window will display no Device code and Select a device for management or data transfer with no detected Android devices listed (Figure 31).

- The screen on the Notebook will continue to display Waiting for connection from host computer (Figure 19).

Verify that the correct Administrator is open in the DDM. Once an Examiner has already been created under an Administrator, the device will no longer accept any additional Administrators unless DANA is uninstalled and then reinstalled resulting in the loss of all data on the Notebook.

o Verify that the Administrator has access to the data under the desired Examiner.

- Complete steps 1 through 2 a. of EDIT EXAMINER AND SUBJECT INFORMATION

- Select View administrators with access to this examiner to generate a list of personnel that are authorized to use the examiner data.

- Compare the list of administrators and signature keys to the administrators opened in the DANA Administrator Manager window of the DDM.

- Without the correct Administrator opened in the DDM, the Data Management PC will be able to recognize the Notebook device but will be unable to connect to it. This is characterized by the following:

- The Manage Device / Import Data window will display the Device code and Could not connect to the device (Figure32).

- The screen on the Notebook will display Host computer may not be authorized to connect to this device or Waiting for connection from host computer.

1. To open the correct Administrator with authorization to access the desired Examiner data, select Open Administrator in the Manage Device / Import Data window.

2. Complete steps 5 and 6 of TRANSFER DATA TO DATA MANAGEMENT $P C$ and close out of the DANA Administrator Manager window.

3. Select Connect to device in the Manage Device / Import Data window (Figure 32).

Verify that the Notebook is on Manage Device screen.

o If the Notebook is not on the Manage Device screen, the Data Management PC will be able to recognize the device but will be unable to connect to it. This is characterized by the following: 
- The Manage Device / Import Data window will display the Device code and Could not connect to the device (Figure32).

1. To get to the Manage device screen on the Notebook, complete step 7 of TRANSFER DATA TO DATA MANAGEMENT PC.

2. Select Connect to device in the Manage Device / Import Data window (Figure 32).

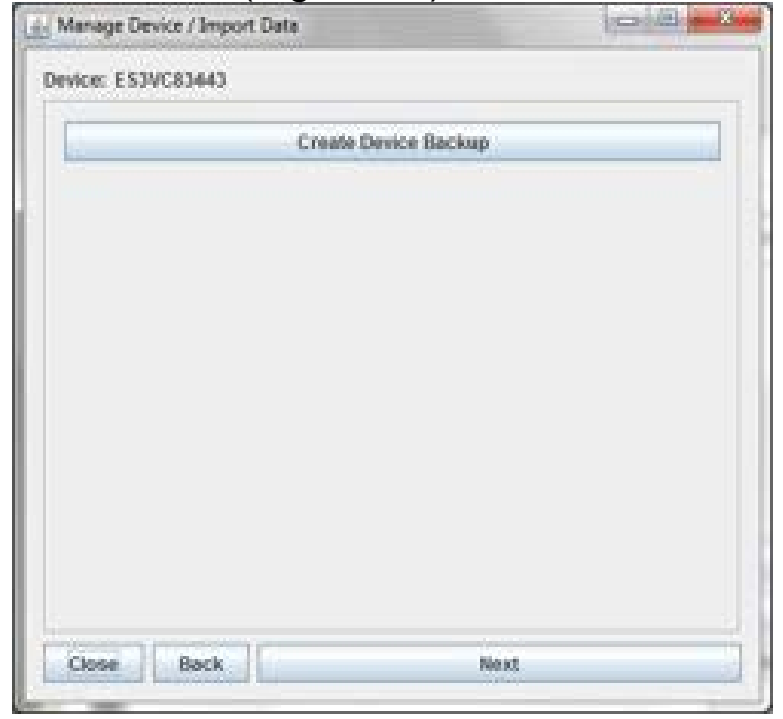

Figure 29



Figure 30

Figure 32

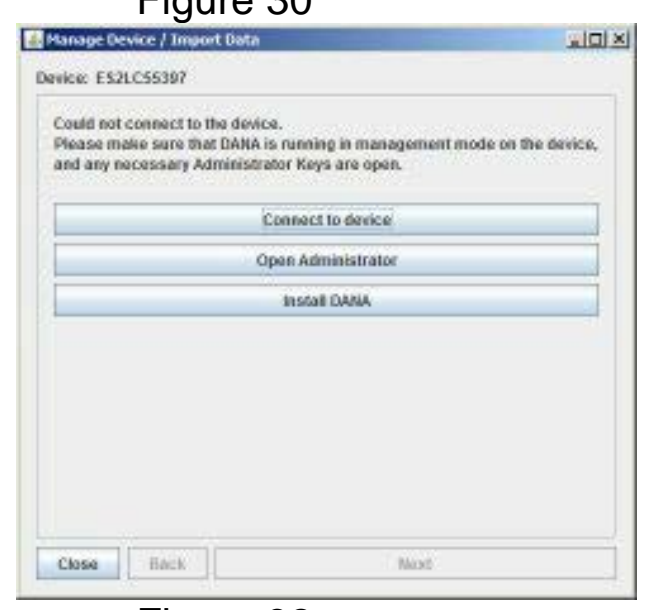

Figure 31

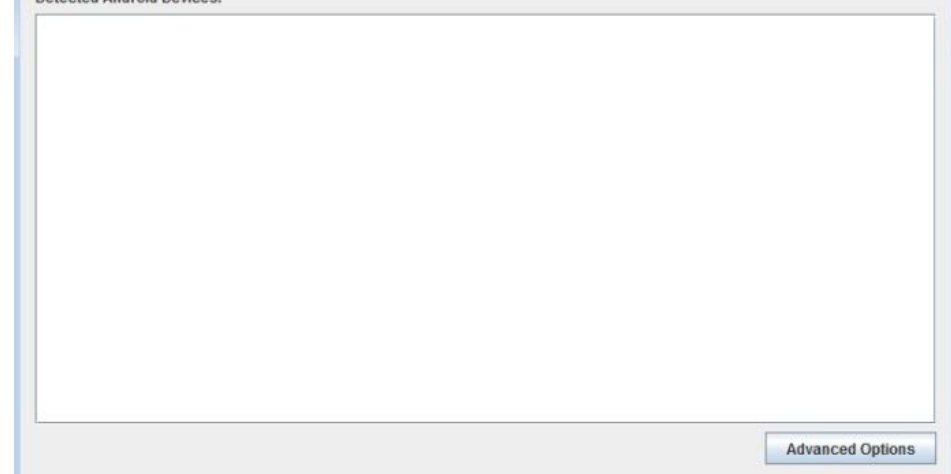

